
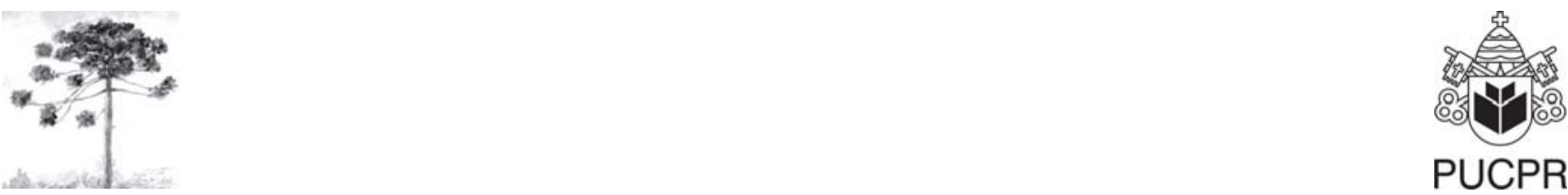

\title{
COMPACTION CHARACTERISTICS OF THE POWDER FROM THE SEED COAT OF TINGUI (Magonia pubescens)
}

\author{
Características de compactação dos pós do envoltório da \\ semente de Tingui (Magonia pubescens)
}

\author{
Antonio Zenon Antunes Teixeira
}

Chemistry Department, Universidade Federal de Mato Grosso (UFMT), Cuiaba, MT - Brazil, e-mail: azteixei1@hotmail.com

\begin{abstract}
The aim of this work was to examine the compaction characteristics of the powder from the seed coat of Tingui (Magonia Pubescens) comparing to the materials commonly used in pellet industries. The materials evaluated as comparison included Microcrystalline cellulose (MCC), Silicified microcrystalline cellulose (SMCC), Hydroxypropyl methylcellulose (HPMC), Polyvinil pirrolidone (PVP) and lactose. The mechanical parameters observed were hardness, tensile strength and deformation. The results confirmed that the powder from the seed coat of Tingui were quietly close to lactose as a soft brittle material.
\end{abstract}

Keywords: Tingui; Magonia pubescens; Compact analysis; Hardness; Deformation.

\section{Resumo}

O propósito deste trabalho foi examinar as características de compactação do pó do envoltório da semente de Tingui (Magonia pubescens) comparando os materiais comumente usados na indústria de peletes. Os materiais avaliados em comparação incluem Celulose microcristalina (MCC), Celulose microcristalina silicificada (SMCC), Hidroxipropil metilcelulose (HPMC), Polivinil pirrolidona (PVP) e lactose. Os parâmetros mecânicos observados foram dureza, força de tensão e deformação. Os resultados confirmam que o pó do envoltório da semente de Tingui era bastante semelhante à lactose como um material macio e quebradiço.

Palavras-chave: Tingui; Magonia pubescens; Análises de compactação; Dureza; Deformação. 


\section{INTRODUCTION}

Studies of protected forests have been done using seedling and when the topographical conditions allow the sowing can be done mechanically, seed pelleting became the main alternative. The seed pelleting allows uniformity of seed size and format; in addition, there is the possibility to use fertilizers, fungicides, insectides (1), herbicides and inoculation of benefit microorganisms. Twelve forest tree species representing three ecological groups were selected for seed pelleting study, confirmed the efficiency of seed pelleting and the mechanical sowing in the establishment of protected riparian forest (2). Seed pelleting of Eucalyptus was also developed considering that the seeds are small and have low yield growth in captivity, thus, seed pelleting could improve the genetic quality of the seeds (3). Pradella et al. (4) studied the seed pelletization of small native seeds Serra do Mar (Leandra cardiophyll, Tibouchina holosericea and Tibuchina pulchra) in hydrophilic gel (sodium alginate). The results showed that pelleting not only improve the seed germination, but also increase the planting application in forestry because of easily handling and transport. However, during transport, the product may lose or gain moistures which may affect its quality. Hence, the resistance of chipping, abrasion or breaking became the main concern in seed pelleting. Compaction is the pelletization process, which the fine particles are formed into pellet in a pellet mill or a process of agglomeration of the particles that are forced together with or without formulation aid (5). Successful compaction of powders requires an understanding of the fundamental properties include both physicochemical and mechanical properties (6). The physicochemical properties including particle size, size distribution, density and angle of repose of the powders determine the flowability. The mechanical properties refer to the compaction properties including hardness (tensile strength) and deformation. These parameters are generally difficult to be altered in contrast to the flowability properties which can be controlled by the technique of milling and agglomeration (7). Tensile strength could give information about the bonding strength and brittleness of the materials (8). Heckel (9) proposed equation to express density in term of packing fraction as a function of applied pressure (5) to determine the deformation behavior of powder under stress. These characteristics are important to establish the effect of dwell time and viscoelasticity on powder compaction and to select the processing tools.

Tingui (Magonia pubescens), trees grow in the savanna regions of Brazil. Its seed coats contain carbohydrates and form hydrogel when immersed in water (10). For being a seed germination promoter, it has antifungal properties against Penicillium, Aspergillus, and Hormodendrum spp. (11) and X-ray fluorescence analysis confirmed Tingui contains high $\mathrm{K}^{+}(12)$. These characteristics prompted the author to evaluate the powder properties of this polysaccharide as an excipient of seed pelleting. Previous study confirmed its physicochemical properties are comparable to HPMC and PVP, polymers commonly used in wettable powder formulation on a wide variety of seeds. This study was to examine the compaction characteristics of the powder from the seed coat of Tingui with comparison to commonly materials used in pellet industries.

\section{MATERIAL AND METHODS}

\section{Materials}

All materials except Tingui were complied with current USP/NF compendial specifications and all were obtained from Toronto Institute Pharmaceutical Technology (TIPT), ON, Canada. Polyvinylpyrrolidone (PVP) (lot \# TX70913), Microcrystalline cellulose (MCC PH 101) (lot \# 04B0204), Silicified Microcrystalline cellulose (SMCC) (lot \# 04B0107), Hydroxypropyl methylcellulose (HPMC) lot \# T98B904 and Lactose monohydrate (lot \# 04B0204). Tingui seeds were collected in the campus of the Federal University of Mato Grosso, Cuiaba, Brazil. The external coat of the seeds was manually isolated from the rest of the seed with the aid of a razor blade and the powder was blended using Mill Pulverizing System AMEF for physical analysis.

\section{METHODS}

\section{Compression}

Compaction was performed using compression machine (Penwalt Stokes) with compaction forces from $1 \mathrm{kN}$ to $25 \mathrm{kN}$. For each compact was weighed on analytical balance ID \# EB003 and then filled into the die. A concavefaced punch n. $21 \times 12 \mathrm{~mm}$ was used. 


\section{Hardness}

A hardness tester (Varian VK 200) was used to determine the load required to diametrically break the compact (crushing strength). The diameter and the thickness were measured using a digital caliper. The tensile strength of the compact was calculated from the compact crushing strength, diameter and thickness.

$$
\sigma \mathrm{x}=2 \mathrm{x} /=\pi \mathrm{dt}(13)
$$

where:

$$
\begin{aligned}
& \sigma \mathrm{x}=\text { tensile strength }(\mathrm{MPa}) \\
& \mathrm{x}=\text { force required }(\mathrm{N}) \\
& \mathrm{d}=\text { diameter of the compact }(\mathrm{mm}) \\
& \mathrm{t}=\text { thickness of the compact }(\mathrm{mm})
\end{aligned}
$$

\section{Heckel analysis}

Heckle analysis was utilized according to the assumption that the powder compression follow first order kinetics. The parameters used for Heckel analysis are true density, weight and compact dimensions. The Heckel equation is (9):

$\ln (1 / 1-\mathrm{D})=\mathrm{k}+\mathrm{A}$

where:

$\mathrm{D}=$ relative density of a powder compact at pressure $(\mathrm{P})$ $\mathrm{k}=$ constant, to measure a plasticity of the compressed material

$\mathrm{A}=\mathrm{Y}$ axis intercept, related to die filling and particle rearrangement before deformation and bonding of the separate particles.

The densities were determined by pycnometry using $n$-hexane at $25^{\circ} \mathrm{C}$. The measured dimensions and weight of each compact were used to calculate the relative densities.

\section{RESULTS AND DISCUSSION}

\section{Hardness}

The effect of compression force on compact strength was summarized in Figure 1. Compact strengths were in order SMCC $>$ MCC $>$ HPMC $>$ PVP $>$ Tingui $>$ Lactose. The results confirmed that the increase of compression force increased the compact hardness. At the same compression force, SMCC produced the hardest compacts whereas lactose produced the softest compacts. Tingui compact were close to lactose. These measurements are useful to provide information for limiting compression forces during processing. A very high slope of a linear relation of compression force versus crushing strength may suggest potential problems in capping since a small change in the pressure could cause significant increases in compact strength.

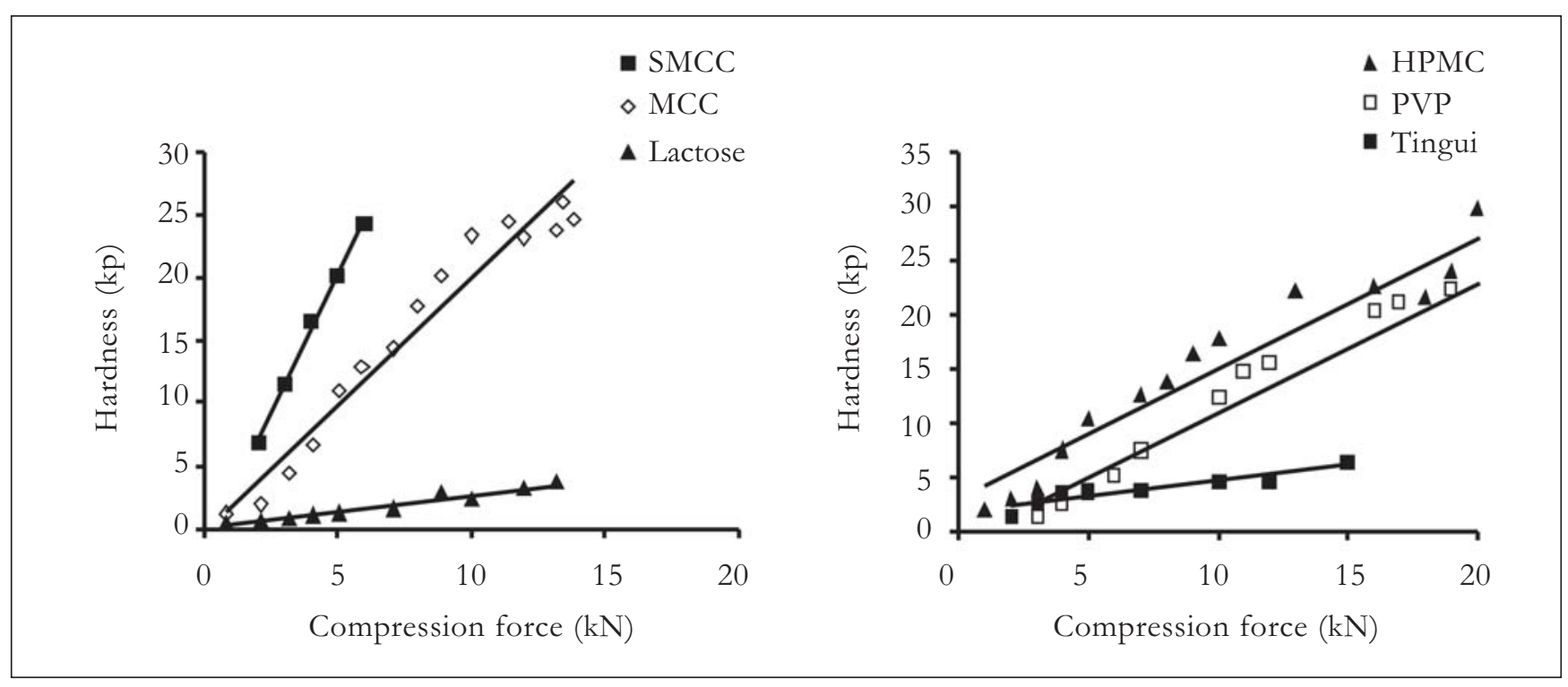

FIGURA 1 - Hardness versus compression force of studied materials 


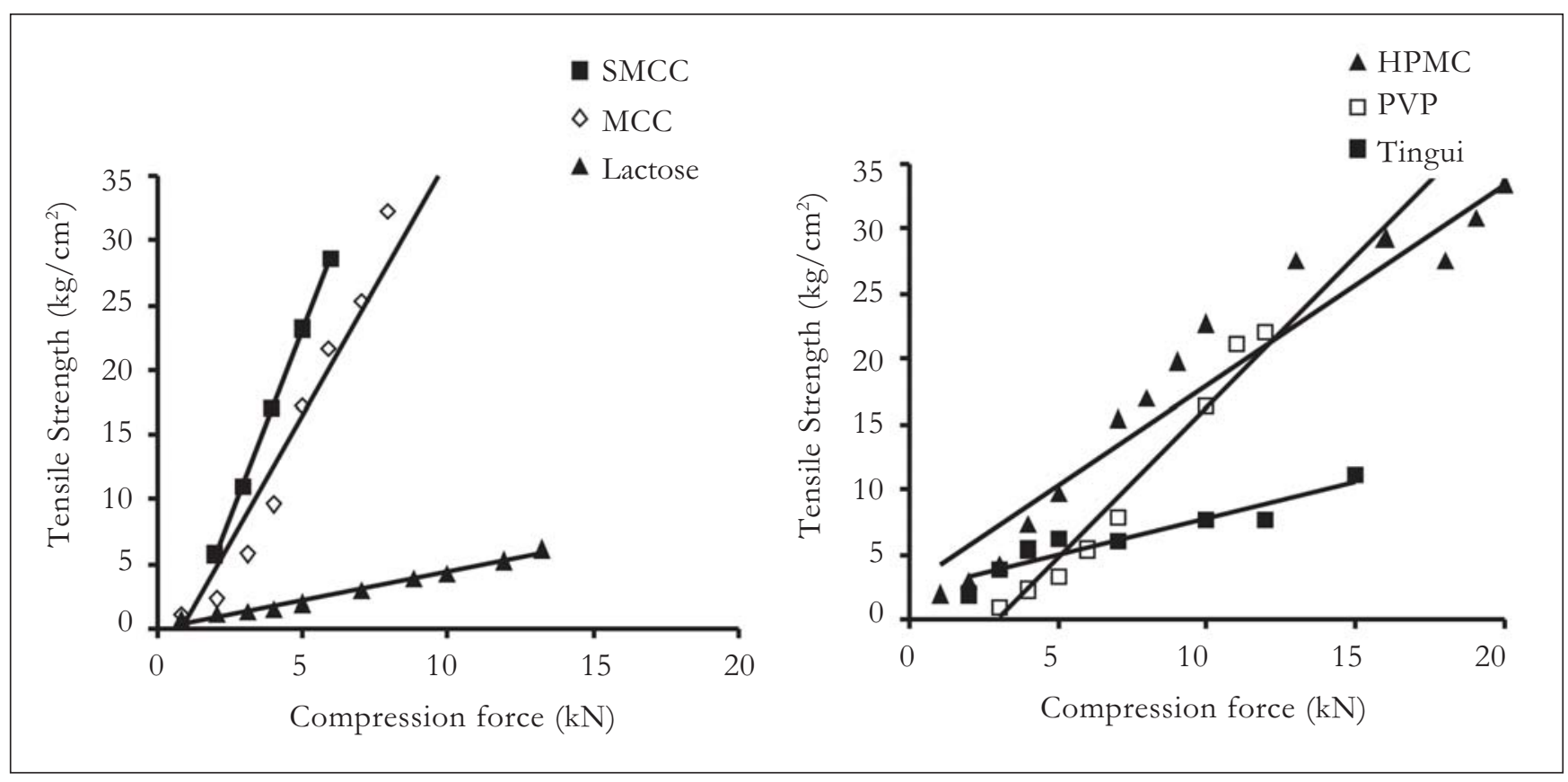

FIGURA 2 - Tensile strength - compression force relationship

A linear relationship between tensile strength and compression pressure was observed from all materials. Figure 2 demonstrated that the tensile strength profiles were decrease in order SMCC $>$ MCC $>$ PVP $>$ HPMC $>$ Tingui $>$ Lactose. The parameters of tensile strength measurement included diameter and thickness of the compact, hence, the variation of the diameter and thickness caused PVP produced higher tensile strength than HPMC. Some authors have suggested that this measurement is sensitive to the variation in the propagation of the crack because the inclusion of the compact thickness in the calculation (6).

The hardness parameters relates to the bonding strength and brittleness of the materials. The higher the bonding index is more potential to the stronger compact and the higher the brittleness index is more likely to the fragmentation. Lactose has been known as a predominantly brittle material that breaks easily at relatively small deformation (14). On the contrary, MCC is known as a ductile material which behaves elastically up to the yield point and plastically beyond that point (7). PVP and HPMC fell in between and Tingui is quite closely to lactose.

\section{Heckel analysis}

Heckel Plot is density-compression force relationship to determine the plastic behavior of the materials. The slope $\mathrm{k}$ relates to the mean yield pressure which is the minimum pressure required to cause deformation. Figure 3 showed that the slope $(\mathrm{k})$ decreases in the following order: SMCC $>$ MCC $>$ PVP $>$ HPMC $>$ Tingui $>$ Lactose. A large value of $\mathrm{k}$ indicates the greater plasticity behavior or plastic deformation at relatively low pressure (9) whereas a small value indicates brittle fracture. 


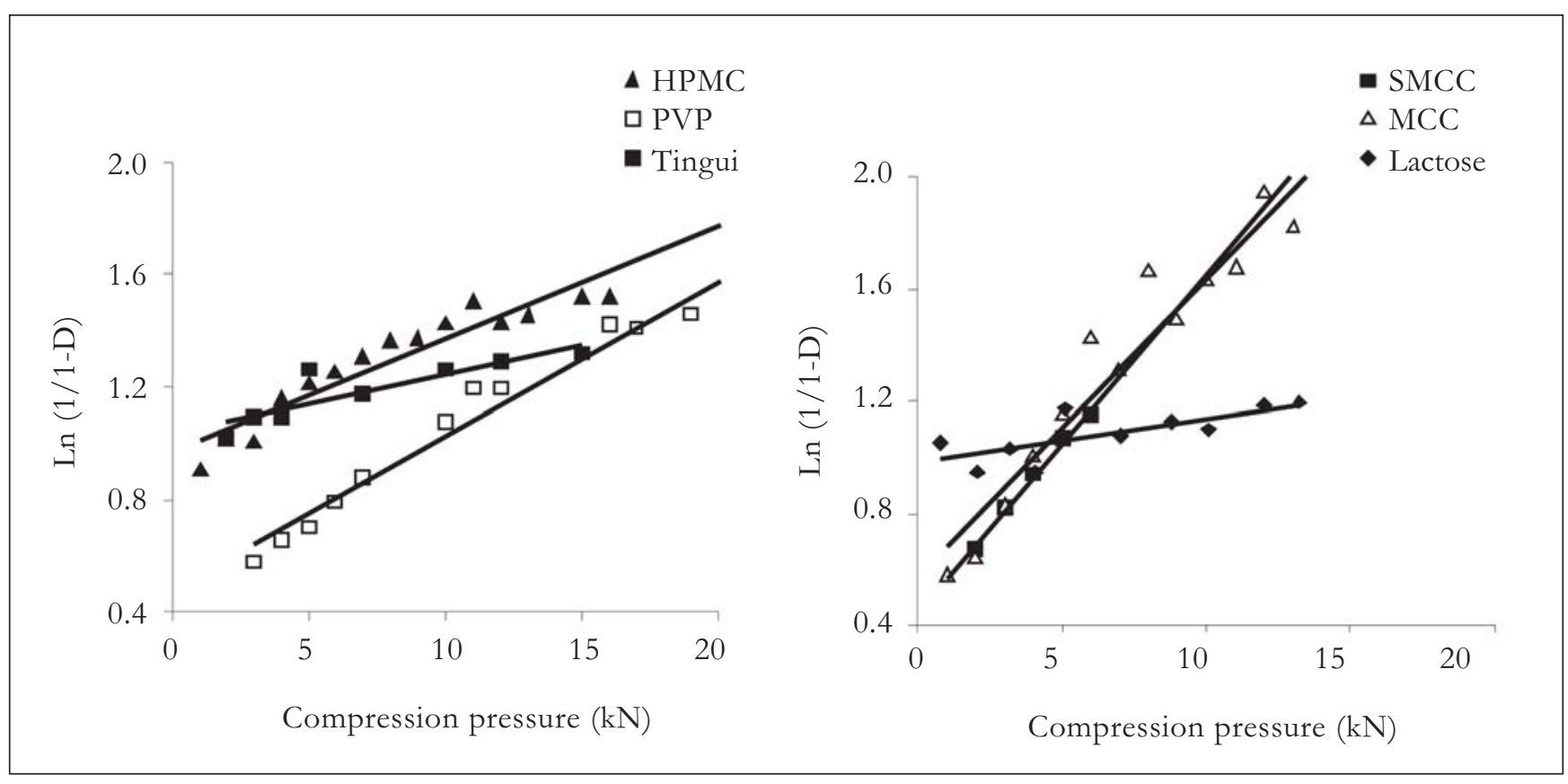

FIGURA 3 - Density - compression pressure relationship according to Heckel Plot

\section{CONCLUSION}

The study confirmed that the mechanical properties of the powder from the seed coat of Tingui are quiet closely to lactose. Tingui performs soft brittle material. Additionally, utilizing of Tingui in the seed pelletization in agriculture or forestry could help to preserve the existence of the cerrado trees.

\section{ACKNOWLEDGEMENT}

The author thanks Mr. Benedito Rodrigues da Silva Ferraz staff from UFMT for collecting the seeds of Tingui and Toronto Institute Pharmaceutical Technology - TIPT for powder physical analysis.

\section{REFERENCES}

1. Costa JLS. Compatibilidade de fungicidas e inseticidas no tratamento de sementes de feijoeiro (Phaseolus vulgaris L.) associadas ou não a polímeros. Santo Antonio de Goiás: Embrapa Arroz e Feijão; 2001.
2. Almeida NO. Establishment of riparian forest by direct plantation, being used seeds pelleting [thesis]. Lavras: Universidade Federal de Lavras; 2004.

3. Kanashiro M, Kageyama PY, Jacob WS. Peletização de sementes de eucalipto. Circular Técnica IPEF. n. 44, Abr. 1979.

4. Pradella DZA, Pompéia SL, Martins SE, Diniz KM, Pradella JGC. Peletização de sementes em gel hidrofílico. Revista Brasileira de Sementes. 1989;11(1):43-52.

5. Tabil, LG. Binding and pelleting characteristics of alfalfa [thesis]. Saskatoon: University of Saskatchewan, Canada; 1996.

6. Jain S. Mechanical properties of powders for compaction and tableting: an overview. PSTT. 1999;2(1):20-30.

7. Maarschalk KVV, Bolhuis GK. Improving properties of materials for direct compaction Part I. Pharm Tech Eur.1998;10(9):30-3.

8. Ghebre-Sellassie I. Mechanism of pellet formation and growth. In: Ghebre-Sellassie I. editor. Pharmaceutical Pelletization Technology. New York: Marcel Decker; 1989. p. 123-43. 
9. Heckel RW. An analysis of powder compaction phenomena. Transactions of the Metallurgical Society of AIME. 1961;221:1001-8.

10. Gorin PAJ, Teixeira AZA, Travassos LR, Labouriau MLS, Iacomini M. Characterization of carbohydrate components of an unusual hydrogel formed by seed coats of Magonia pubescens (Tingui). Carbohy Res. 1996;282:325-33.

11. Labouriau MLS. A semente de Magonia pubescens St. Hil: Morfologia e germinação. Academia Brasileira de Ciências. 1973;45 (3-4):501-36.

12. Teixeira AZA. Evaluation of powder properties from the seed coat of tingui as an excipient for seed pelleting. (Submitted for publication).

13. Fell JT, Newton JM. The tensile strength of lactose tablets. J Pharm Pharmacol. 1968;20(8):657-758.

14. Rowe RC, Roberts RJ. Mechanical properties. In: Alderborn G, Nyström C. Pharmaceutical powder compaction technology. New York: Marcel Decker; 1996. p. 283-322.

Received: 01/15/2007

Recebido: 15/01/2007

Approved: 02/22/2007

Aprovado: 22/02/2007 